\title{
Androgenic Regulation of Gap Junctions Between Motoneurons in the Rat Spinal Cord
}

\author{
Akira Matsumoto, ${ }^{1,2}$ Arthur P. Arnold, ${ }^{2}$ Guido A. Zampighi, ${ }^{1}$ and Paul E Micevych ${ }^{1}$ \\ Departments of ${ }^{1}$ Anatomy and ${ }^{2}$ Psychology, and Laboratory of Neuroendocrinology, Brain Research Institute, University of \\ California, Los Angeles, California 90024
}

\begin{abstract}
Gap junctional plaques were found between androgen-sensitive motoneurons of the spinal nucleus of the bulbocavernosus (SNB), using thin-section and freeze-fracture techniques. The somata and proximal dendrites of SNB motoneurons were studied after retrograde labeling with cholera toxin conjugated to HRP. Of the gap junctions observed, $45 \%$ were somatodendritic, $35 \%$ were dendrodendritic, and $20 \%$ were somatosomatic. The removal of testosterone by castration dramatically reduced the number and diameter of the junctional plaques, and these changes were prevented by testosterone treatment. The results are the first demonstration of hormonal regulation of morphologically identified gap junctions in the CNS. The occurrence and hormonal dependence of gap junctional plaques between motoneurons of the lumbar spinal cord indicate that androgens regulate the degree of coupling between these cells, which may allow for the synchronization and amplification of the electrical activity in the nucleus.
\end{abstract}

The spinal nucleus of the bulbocavernosus (SNB) is a cluster of about 200 large androgen-accumulating motoneurons located in the fifth and sixth lumbar segments of the spinal cords of male rats (Breedlove and Arnold, 1980). These motoneurons innervate 3 target muscles, the bulbocavernosus (SNB), levator ani, and the anal sphincter (Breedlove and Arnold, 1980; Schroder, 1980; McKenna and Nadelhaft, 1986). The bulbocavernosus and levator ani attach to the penis and play an important role in male copulatory behavior, which is sensitive to alterations in circulating levels of androgen in adulthood (Sachs, 1982; Hart and Melese-d'Hospital, 1983). After castration of adult males, both somatic size (Breedlove and Arnold, 1981) and dendritic length (Kurz et al., 1986; Forger and Breedlove, 1987) of the SNB motoneurons are significantly reduced, and androgen replacement in castrates prevents this reduction. In addition, castration dramatically reduces the number and size of chemical synapses onto the somatic and dendritic membranes (Leedy et al., 1987; Matsumoto et al., 1987). In the course of our study (Matsumoto et al., 1987), we observed regions where SNB somata come into close contact with other somatic or

\footnotetext{
Received Oct. 30, 1987; revised Mar. 7, 1988; accepted Mar. 8, 1988.

We wish to thank Jean Lee, Toni Alexander, and Mike Kreman for their excellent technical assistance and Cynthia Jordan for assistance with statistical analysis. This study was supported by NIH Grants NS23468 and HD15021.

Correspondence should be addressed to Dr. Paul E Micevych, Department of Anatomy, UCLA School of Medicine, Los Angeles, CA 90024-1763. Copyright @ 1988 Society for Neuroscience $0270-6474 / 88 / 114177-07 \$ 02.00 / 0$
}

dendritic membranes. These zones of contact have previously been described as points of adherence, or puncta adherentia, which does not imply functional coupling (Kerns and Peters, 1974; Anderson et al., 1976; Bellinger and Anderson, 1987a, b). However, electrotonic coupling has been demonstrated between neonatal lumbar motoneurons (Fulton et al., 1980; Arasaki et al., 1984). This finding led us to examine whether there was morphological evidence for gap junctions that might mediate such electrical communication, and if so, whether the gap junctions were regulated by androgen.

Gap junctions, or electrical synapses, are specialized regions of contact composed of channels that permit the passage of ions and small molecules between adjacent cells, as demonstrated by dye-coupling experiments (Flagg-Newton et al., 1979). This kind of direct intercellular communication facilitates the coordination of growth and metabolism of the cells and/or synchronization of their electrical activity (for reviews, see Loewenstein, 1981; Spray and Bennett, 1985). Gap junctions were first recognized in large motoneurons in the CNS of invertebrates and fish using ultrastructural (Hama, 1961; Robertson, 1963), electrophysiological (Furshpan and Potter, 1959; Bennett et al., 1963; Furshpan, 1964), or dye-coupling techniques (Payton et al., 1969; Andrew et al., 1981). Motoneuronal gap junctions and electrical coupling of spinal motoneurons have now been studied extensively in anurans, but also in fish, reptiles, and mammals (Washizu, 1960; Grinnell, 1966, 1970; Nelson, 1966; Sotelo and Taxi, 1970; Schnitzlein and Brown, 1975; Gogan et al., 1977; Waxman, 1979; Erulkar and Soller, 1980; Collins, 1983).

In gonadal steroid-sensitive tissues, including the rodent ovary, uterine myometrium, and paraventricular hypothalamic nucleus, evidence is accumulating that sex steroids play a significant role in modulating intercellular communication via gap junctions (Bergman, 1968; Merk et al., 1972; Dahl and Berger, 1978; Garfield et al., 1980; Burghardt and Anderson, 1981; Demianczuk et al., 1984; MacKenzie and Garfield, 1985; Cobbett et al., 1987). Because androgen regulates the amount of somatic and dendritic membrane area in SNB motoneurons (Breedlove and Arnold, 1981; Kurz et al., 1986), as well as the amount of afferent synaptic contact and dendrosomatic membrane apposition in this nucleus (Leedy et al., 1987; Matsumoto et al., 1987), the present study was conducted to determine whether androgen also alters the number of gap junction channels between the cells of the SNB. We found that the removal of testosterone by castration reduces the number and diameter of the gap junctional plaques and that these changes were prevented by testosterone treatment. 


\section{Materials and Methods}

Fifteen adult male Sprague-Dawley rats were used in the present study. Male rats were castrated and implanted subcutaneously with Silastic capsules (Dow Corning, i.d. $1.57 \mathrm{~mm}$, o.d. $3.18 \mathrm{~mm}, 45 \mathrm{~mm}$ long) containing testosterone (Steraloids) or nothing. Sham-castrated animals served as controls. There were 5 animals in each group. Four weeks after castration, $0.2 \%$ cholera toxin-horseradish peroxidase (CT-HRP, List Biological Laboratories, Campbell, CA) was injected bilaterally into the bulbocavernosus muscles $(1 \mu \mathrm{l} / \mathrm{side})$ under Nembutal anesthesia. Two days after CT-HRP injection, all animals were anesthetized with Nembutal and perfused transcardially with $200 \mathrm{ml} 0.9 \% \mathrm{NaCl}$ and subsequently with a mixture of $4 \%$ paraformaldehyde and $0.2 \%$ glutaraldehyde in $1000 \mathrm{ml} 0.1 \mathrm{M}$ sodium phosphate buffer (pH 7.2). The body and seminal vesicle weights were recorded before and after autopsy, respectively. The lumbar portion of the spinal cord in each animal was removed and cut transversely with a Vibratome (Lancer Instruments, St. Louis) into $50 \mu \mathrm{m}$ sections. The sections were processed according to a modification of the tetramethylbenzidine method (Matsumoto et al., 1988). The sections were postfixed in $1 \% \mathrm{OsO}_{4}$ in $0.15 \mathrm{M}$ sodium cacodylate buffer (pH 7.2) for $1 \mathrm{hr}$ at room temperature. After staining with an aqueous solution of $1 \%$ uranyl acetate, the tissue sections were dehydrated in graded ethanols and embedded in Epon 812. Thick sections of the spinal cords were counterstained with toluidine blue and examined under the light microscope to identify the existence of CTHRP in the cytoplasm of the SNB motoneurons. Thin sections (interference color silver-gold, about $90 \mathrm{~nm}$ thick) adjacent to these thick sections were cut and stained with lead citrate. All observations were performed in a 7eiss FM 109 electron microscope.

To analyze the incidence of gap junctions, we selected at random one ultrathin section through the soma and nucleus from each of 10 labeled SNB neurons in each spinal cord. On these thin sections, the somatic and proximal dendritic membranes were surveyed in the electron microscope at $50,000 \times$. In general, the proximal dendritic membranes sampled were within one soma's diameter of the cell body. Each gap junction was photographed, and its length was measured at a final magnification of $93,750 \times$ using a digitizing tablet and microcomputer. Statistical analysis was made by analysis of variance (ANOVA), with $n=$ the number of animals in each group.

Freeze-fracture. An intact adult male rat was perfused transcardially with $4 \%$ paraformaldehyde and $1 \%$ glutaraldehyde in a $0.1 \mathrm{M}$ sodium phosphate buffer ( $\mathrm{pH}$ 7.6). The lumbosacral spinal cord was removed and immersed in the same fixative overnight at $4^{\circ} \mathrm{C}$, then transferred to sodium phosphate buffer. Transverse, $50 \mu \mathrm{m}$ sections were cut on a vibrating microtome (Lancer Inc.) and placed in $20 \%$ sucrose solution in $0.1 \mathrm{M}$ sodium phosphate buffer for $1 \mathrm{hr}$ then changed to a $20 \%$ glycerol solution for an additional hour. Under a dissecting microscope, the SNB was dissected from the spinal cord sections, placed on standard Balzer holders, and plunged into liquid propane cooled to $-190^{\circ} \mathrm{C}$ with liquid nitrogen. The frozen specimens were transferred to a Balzer $400 \mathrm{~K}$ freezefracture apparatus and fractured with a knife cooled at liquid nitrogen temperature at a pressure of $10^{-7}$ Torr and a temperature of $-120^{\circ} \mathrm{C}$. The fractured SNB nuclei were immediately replicated with platinumcarbon at $45^{\circ}$ unidirectionally, and with carbon at $90^{\circ}$ with rotation to provide a strong support film. The replicas were floated onto water, cleaned in bleach, and mounted on single-hole Formvar-coated grids.

\section{Results}

Both ultrastructural techniques indicated the presence of gap junctions in the SNB nucleus. In thin sections, gap junctions were found immediately adjacent to or between desmosomelike junctions on CT-HRP-labeled SNB motoneuronal membranes that were apposed to somatic or dendritic membranes (Fig. 1). The gap junctions displayed characteristic pentalaminar structures, about $15 \mathrm{~nm}$ in overall thickness, composed of 3 dense bands separated by 2 clear bands. The central dense band, which contains the extracellular gap, had a somewhat beaded appearance suggestive of the periodic array of particles typical of gap junctions. Amorphous electron-dense material was found associated with the cytoplasmic sides of the gap junction in both cells, separated from the junction by a clear space of about 7 $\mathrm{nm}$. These structural features of gap junctions in the SNB are similar to those described in other regions of the mammalian CNS (Robertson, 1963; Brightman and Reese, 1969; Sotelo and Korn, 1978), as well as gap junctions from liver and cardiac muscle (Revel and Karnovsky, 1967; Zampighi et al., 1980).

Freeze-fracture replicas of the isolated SNB region demonstrated plaques of intramembrane particles on the protoplasmic (PF) and complementary pits on the extracellular (EF) fracture faces. This fracture pattern is characteristic of mammalian gap junctions (Chalcroft and Bullivant, 1970; McNutt and Weinstein, 1970; Peracchia, 1980; Larsen, 1983). Figure 2 shows a "P-E" transition in the SNB nucleus, in which the PF face contained clusters of intramembranous particles spaced $7 \mathrm{~nm}$ center to center, a distance similar to the spacing of the complementary pits in the PE face. These particles formed somewhat irregular, closely packed clusters, although small areas with clear hexagonal symmetry were also found in the EF face. Because gap junctions are symmetric structures with respect to the extracellular gap, the "P-E" transition represents the jump from the $\mathrm{EF}$ face of one cell to the PF face of an apposed cell including the extracellular gap. Therefore, the study of the P-E transitions permit one to estimate the width of the extracellular gap, which is necessary to demonstrate that these clusters of particles and pits correspond to gap junction regions. In the SNB, the step separating the array of pits in the EF face and the particles in the PF face was much smaller than when the fracture plane jumped across an adjacent nonjunctional region. This observation provided further evidence that the extracellular gap at the arrays of particles and pits seen in freeze-fracture replicas corresponded to the regions of close membrane apposition described from the thin sections (Fig. 1).

Thin sections of the SNB allowed quantification of the distribution of gap junctions. A total of 40 gap junctions were observed on the 150 neuronal perimeters sampled in the 3 groups. Some junctions were found between 2 cells labeled with CTHRP, indicating that both were motoneurons innervating the bulbocavernosus muscle. Of the 40 gap junctions observed, $20 \%$ were between 2 somata, $45 \%$ were between a soma and a dendrite, and $35 \%$ were between 2 dendrites.

Castration and androgen treatment dramatically altered the frequency and size of gap junctions (Table 1). The number of gap junctions $(p<0.0005)$, number of neurons with gap junctions $(p<0.01)$, and length of gap junctions $(p<0.0005)$ were reduced by castration. Treatment with testosterone for 4 weeks after castration prevented this decline, so that these measures were similar in testosterone-treated and sham-castrated males.

The measurements of the size and frequency of gap junctions make possible a calculation of the number of gap junctions found on the soma and proximal dendrites of a typical SNB motoneuron under each hormonal condition (Table 2). Because the thin sections used in the present study were cut from the same blocks used by Matsumoto et al. (1988), we used the average membrane length sampled in each group in that study as a reasonable estimate of the membrane lengths sampled in the present study. The surface membrane area of the soma and proximal dendrites was calculated on the assumption that the soma and proximal dendrites formed a sphere whose circumference was equal to the perimeter measured by Matsumoto et al. (1988). Although this calculated area is an overestimate because the SNB somata are not perfect spheres, it is acceptable for approximate comparison of the groups. The area occupied by gap junctions on this membrane surface was calculated by assuming that the measured mean length (Table 1) corresponds 


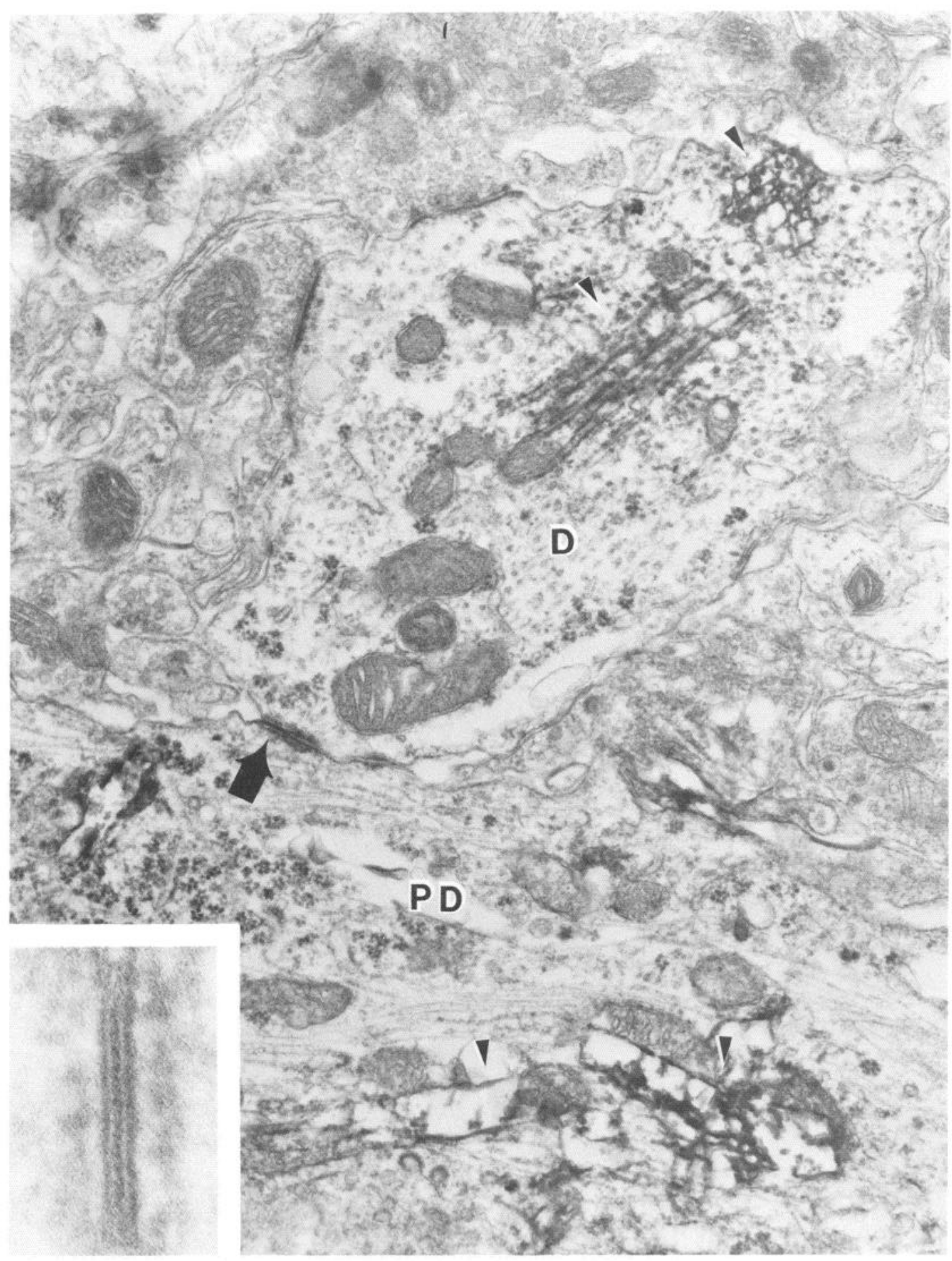

Figure 1. A gap junction (arrow and inset) can be seen along the apposed membranes of a proximal dendrite $(P D)$ of an SNB motoneuron and another SNB dendrite $(D)$ in a testosterone-treated male rat 4 weeks after castration. CT-HRP crystals (arrowheads) are found in both dendrites, indicating that both are motoneurons projecting to the bulbocavernosus muscle. $\times 31,700$ (inset: $\times 338,500$ ).

to the mean diameter of the gap junctional plaques. These values were used to estimate the percentage of the somatic and proximal dendritic membrane occupied by gap junctions, and the number of gap junctions found onto an average SNB soma with its proximal dendrites. These calculations indicate that the percentage of SNB membrane occupied by gap junctions was about 6 times greater in the 2 groups with high titers of androgen than in the castrated group. Moreover, the number of gap junctional plaques per neuron in castrates was approximately one-half that in the other groups. These results suggest that castration reduced both the size and number of gap junctions and that androgen treatment prevented this effect.

\section{Discussion}

The present study utilizes both thin section and freeze-fracture electron microscopic techniques to demonstrate that the SNB motoneurons that project to the bulbocavernosus muscle possess gap junctions on their somatic and proximal dendritic mem- 


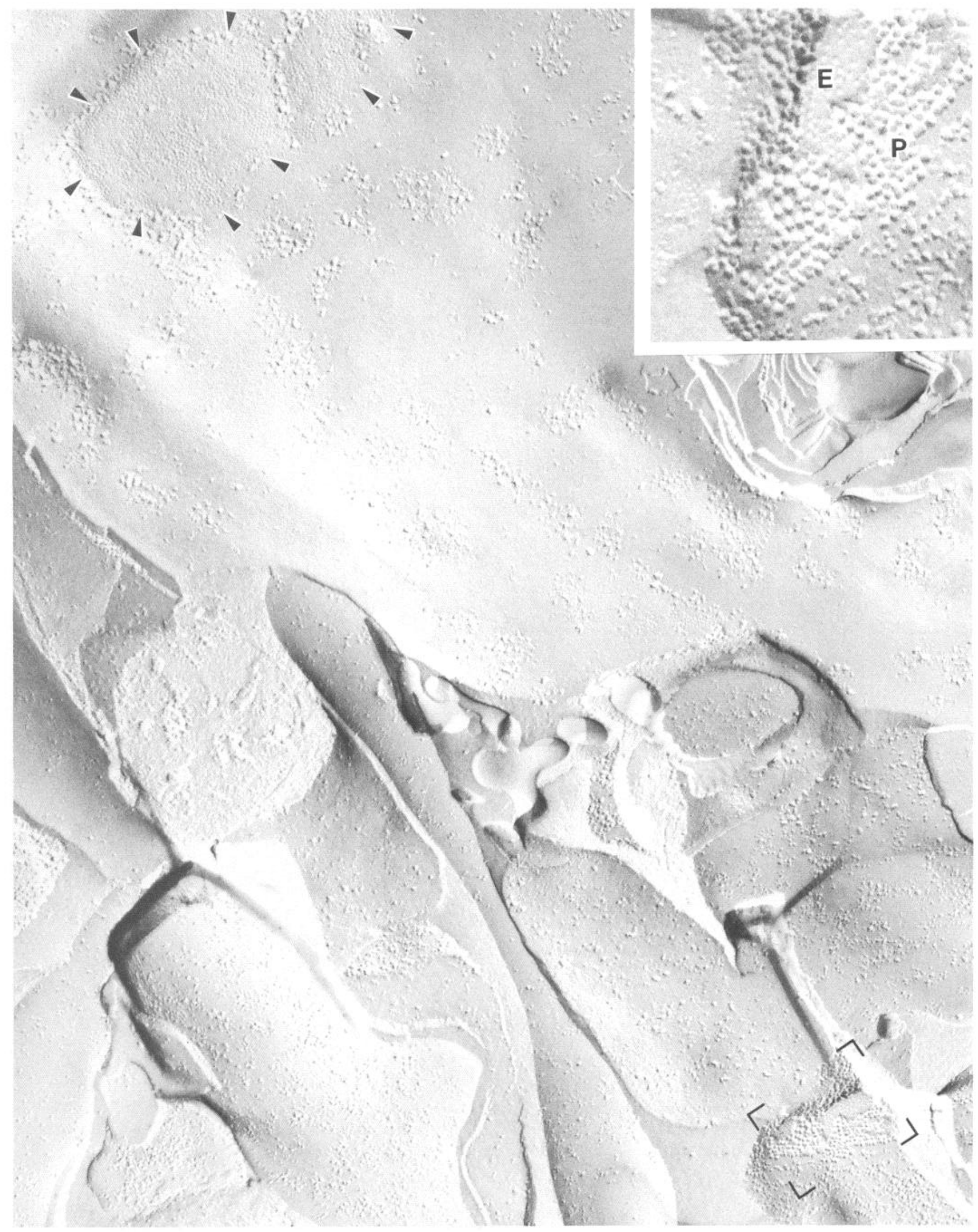

Figure 2. Freeze-fracture replica from the SNB region. The PF and EF fracture faces represent fractures through the bilayer of the cell membrane, viewed from either the extracellular (EF) or intracellular (PF) side. The extensive EF face at the top of the figure corresponds to a fracture through the plasma membrane of the soma, whereas the numerous irregular and curved faces in the bottom half may be mostly from dendrites. The EF 
branes. Both techniques indicate the presence of gap junctions in the SNB nucleus, and the thin section analysis establishes that the gap junctional plaques are larger and more frequent when androgen levels are high than when levels are low. Because the size of the plaques is related to the number of gap junctional channels between the cells (Unwin and Zampighi, 1980), our results indicate that androgen regulates the total number of gap junction channels in these motoneurons and the degree of electrical coupling between them. Because adult SNB motoneurons are thought to contain androgen receptors (Breedlove and Arnold, 1980, 1983), the testosterone-induced effect on the number of gap junctional channels may be the result of the interaction of androgen with the SNB neurons rather than with other target cells.

Our calculations of numbers and sizes of gap junctional plaques in SNB motoneurons (Table 2) are likely to be underestimates. Small junctional plaques, composed of 50-100 channels, most likely were overlooked in thin sections because their visibility depends on the orientation with respect to the plane of section and the thickness of the section. Moreover, because the somata and dendrites were not perfect spheres (as was assumed to simplify calculations), their total membrane areas were overestimated. Both errors lead to an underestimate of the numbers and sizes of junctional plaques in all groups.

Gap junctional plaques were never observed between an SNB motoneuron and glial cell in thin sections, suggesting that motoneuronal junctional plaques couple 2 neurons. Gap junctions were found between CT-HRP-labeled motoneurons, demonstrating that motoneurons projecting to the bulbocavernosus are electrically and/or metabolically coupled to each other. However, CT-HRP-labeled motoneurons also possess gap junctions to nonlabeled neurons. Although some of these unlabeled neurons could project to the bulbocavernosus, some of the nonlabeled somata or processes are probably other SNB motoneurons that innervate the levator ani or anal sphincter muscles (Schroder, 1980; McKenna and Nadelhaft, 1986). This observation suggests that heteronymous SNB motoneurons may also be electrically or metabolically coupled. Moreover, SNB motoneurons may be coupled on opposite sides of the spinal cord since SNB dendrites cross the midline and pass close to the contralateral SNB motoneurons (Rose and Collins, 1985; Kurz et al., 1986). Similar contralateral coupling has been observed in frogs (Erulkar and Soller, 1980).

The dendrites of androgen-sensitive motoneurons in the SNB and the lateral lumbar motor column are known to form dense bundles in which the dendrites of motoneurons come into close apposition (Kerns and Peters, 1974; Anderson et al., 1976; Bellinger and Anderson, 1987a, b). These previous studies noted frequent puncta adherentia along apposed dendritic membranes, and on membranes separating somata and dendrites, or two somata. Our results imply that at least some of the structures previously identified as puncta adherentia are gap junctions. Because our study focused on the somata and proximal dendrites of SNB neurons, the present results do not tell us if gap junctions are present in the thick dendritic bundles. If such gap junctions
Table 1. Effect of androgen on the incidence and size of gap junctions between SNB motoneurons in control and experimental animals

\begin{tabular}{|c|c|c|c|c|}
\hline Group & $\begin{array}{l}\text { Rats } \\
(n)\end{array}$ & $\begin{array}{l}\text { Neuronal } \\
\text { perimeters } \\
\text { containing } \\
\text { gap } \\
\text { junctions } \\
(n) \\
\end{array}$ & $\begin{array}{l}\text { Gap } \\
\text { junctions } \\
\text { per animal } \\
(n)\end{array}$ & $\begin{array}{l}\text { Length of p- } \\
\text { gap junctions } \\
\text { (nm) }\end{array}$ \\
\hline Sham castrates & 5 & $2.6 \pm 0.4$ & $3.4 \pm 0.4$ & $168.8 \pm 25.2$ \\
\hline Castrates & 5 & $0.8 \pm 0.2^{a}$ & $1.0 \pm 0.3^{b}$ & $64.7 \pm 8.1^{a}$ \\
\hline \multicolumn{5}{|l|}{ Castrates } \\
\hline+ testosterone & 5 & $2.8 \pm 0.5$ & $3.6 \pm 0.2$ & $154.4 \pm 19.1$ \\
\hline
\end{tabular}

Means \pm SEM are given.

${ }^{a} p<0.001$.

${ }^{b} p<0.0005$ (versus controls or castrates + testosterone).

exist in the large distal dendritic trees of these motoneurons, they may contribute further to the electrical coupling between motoneurons. The dense packing of SNB somas and dendrites is similar to that seen in some other mammalian brain regions where gap junctions have been observed, such as in glomeruli of the olfactory bulb or of the inferior olivary nucleus, or the lateral vestibular, inferior olivary, or mesencephalic trigeminal nuclei (Baker and Llinás, 1971; Pinching and Powell, 1971; Korn et al., 1973; Llinás et al., 1974).

The importance of androgen in regulation of the size and number of gap junctional plaques suggests that one of androgen's roles is to enhance electrical coupling of SNB neurons so that excitatory afferent input to part of the SNB motoneuron pool might cause depolarization of the entire SNB nucleus and promote synchronous firing of all SNB motoneurons. Thus, this neuromuscular system seems adapted for highly synchronized, all-or-none contractions rather than finely graded contractions. Such synchronized activity might be particularly suited to the sexual function of these muscles, since the bulbocavernosus and levator ani muscles attach exclusively to the penis and are active during erection and ejaculation (Purohit and Beckett, 1976; Beckett et al., 1975, 1978). Copulation is stimulated by androgen, and androgen increases the frequency of sexual reflexes that involve contractions of these muscles (Hart, 1967, 1973; Sachs 1982; Hart and Melese-d'Hospital, 1983). Thus, androgen-induced coupling of the SNB motoneurons may be one mechanism by which androgen stimulates copulatory function.

The present results indicate that gap junctions persist in castrated male rats, even 4 weeks after castration, although the number and area of gap junctional plaques (i.e., number of junctional channels) has decreased dramatically by this time. One possible consequence of this dramatic reduction of channels may be that the neurons are no longer sufficiently coupled for electrical activity but remain metabolically coupled. In the castrated rat, the time course of coupling of SNB cells may be increased enough so that only slow events would be faithfully communicated via the gap junctions.

face of the soma contains large particles, some of which are arranged in irregular clusters (probably desmosomes, see Fig. 1), and plaques of small pits, which are gap junctions. The gap junctional plaques can contain many pits (areas encircled by the arrowheads) or just a few (not indicated). Inset, The protoplasmic-extracellular (P-E) transition from the bottom right corner. Note that at this transition the PF and EF faces are separated by a small step which includes the narrow extracellular gap of the junction. $\times 71,300$ (inset: $\times 149,500$ ). 
Table 2. Calculation of frequency of gap junctions on somatic and proximal dendrites of SNB neurons

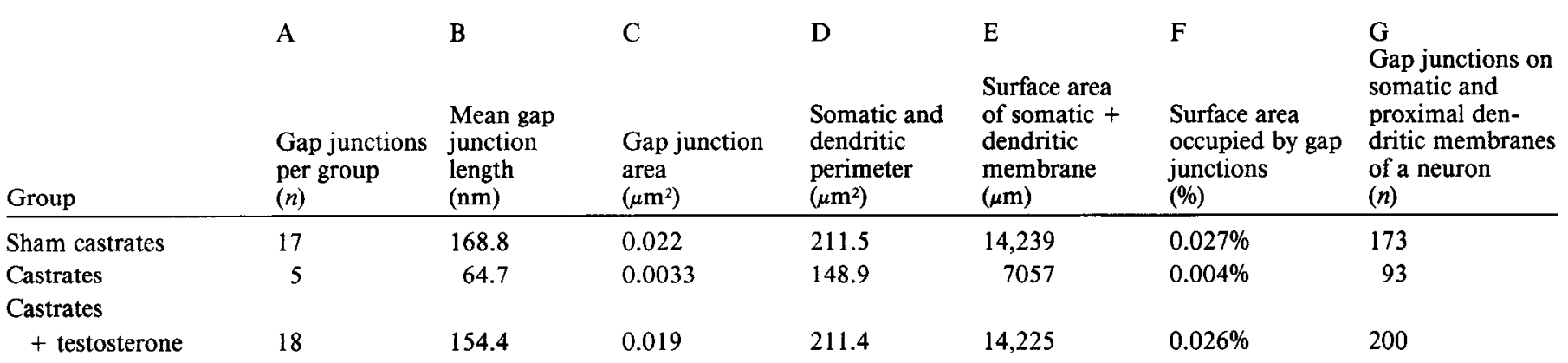

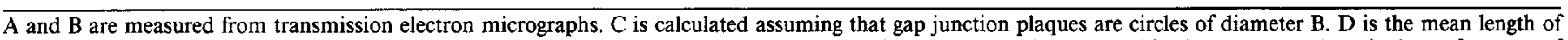

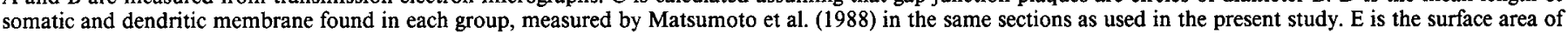

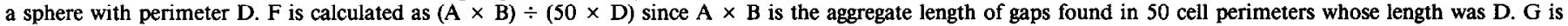
calculated as $\mathrm{E} \times \mathrm{F} / \mathrm{C}$.

The present results add to the list of cell types in which gonadal steroids regulate the size or frequency of gap junctional plaques. For example, estrogen increases gap junctions between granulosa cells of the rat ovary (Merk et al., 1972; Burghardt and Anderson, 1981), and between smooth muscle cells of rodent uterus (Bergman, 1968; Dahl and Berger, 1978; Garfield et al., 1980; Merk et al., 1980; Demianczuk et al., 1984; MacKenzie and Garfield, 1985). Testosterone stimulates Lucifer yellow dye coupling between magnocellular neurons in the paraventricular nucleus of the rat hypothalamus (Cobbett et al., 1987). On the other hand, female Xenopus frogs possess dye-coupled laryngeal muscle fibers, whereas adult males do not (Tobias and Kelley, 1988). Androgen treatment of females reduces the coupling in females. This evidence, together with the present report, indicates that gonadal steroids regulate the number of gap junction channels in a wide variety of reproductive tissues, including the gonads, nervous system, and smooth and striated muscles. These tissues have in common the presence of steroid hormone receptors. Indeed, it becomes reasonable to ask whether steroid control of gap junctions and electrical coupling is a common feature of all such steroid-sensitive cells.

\section{References}

Anderson, W. J., M. W. Stromberg, and E. J. Hinsman (1976) Morphological characteristics of dendritic bundles in the lumbar spinal cord of the rat. Brain Res. 110: 215-227.

Andrew, D. R., B. A. McVicar, F. E. Dudek, and G. I. Hatton (1981) Dye transfer through gap junctions between neuroendocrine cells of the rat hypothalamus. Science $211: 1187-1189$.

Arasaki, K., N. Kudo, and T. Nakanishi (1984) Firing of spinal motoneurons due to electrical interaction in the rat: An in vitro study. Exp. Brain Res. 54: 437-445.

Baker, R., and R. Llinás (1971) Electrotonic coupling between neurones in the rat mesencephalic nucleus. J. Physiol. (Lond.) 212: 4563.

Beckett, S. D., D. F. Walker, R. S. Hudson, T. M. Reynolds, and R. C. Purohit (1975) Corpus spongiosum penis pressure and penile muscle activity in the stallion during coitus. Am. J. Vet. Res. 36: 431-433.

Beckett, S. D., T. M. Reynolds, and J. E. Bartels (1978) Angiography of the crus penis in the ram and buck during erection. Am. J. Vet. Res. 39: 1950-1954.

Bellinger, D. L., and W. J. Anderson (1987a) Postnatal development of cell columns and their associated dendritic bundles in the lumbosacral spinal cord of the rat. I. The ventrolateral cell column. Dev. Brain Res. 35: 55-67.

Bellinger, D. L., and W. J. Anderson (1987b) Postnatal development of cell columns and their associated dendritic bundles in the lumbosacral spinal cord of the rat. II. The ventromedial cell column. Dev. Brain Res. 35: 69-82.
Bennett, M. V. L., E. Aljure, Y. Nakajima, and G. D. Pappas (1963) Electronic junctions between teleost spinal neurons: Electrophysiology and ultrastructure. Science 141: 262-264.

Bergman, R. A. (1968) Uterine smooth muscle fibers in castrate and estrogen-treated rats. J. Cell Biol. 36: 639-648.

Breedlove, S. M., and A. P. Arnold (1980) Hormone accumulation in a sexually dimorphic motor nucleus of the rat spinal cord. Science 210: 564-566.

Breedlove, S. M., and A. P. Arnold (1981) Sexually dimorphic motor nucleus in rat spinal cord: Response to adult hormone manipulation, absence in androgen insensitive rats. Brain Res. 225: 297-307.

Breedlove, S. M., and A. P. Arnold (1983) Sex differences in the pattern of steroid accumulation of motoneurons of the rat lumbar spinal cord. J. Comp. Neurol. 215: 211-216.

Brightman, M. W., and T. S. Reese (1969) Junctions between intimately apposed cell membranes in the vertebrate brain. J. Cell Biol. 40: 648-677.

Burghardt, R. C., and E. Anderson (1981) Hormonal modulation of gap junctions in rat ovarian follicles. Cell Tissue Res. 214: 181-193.

Chalcroft, J. P., and S. Bullivant (1970) An interpretation of liver cell membrane and junction structure based on observation of freezefracture replicas of both sides of the fracture. J. Cell Biol. 47: 49-60.

Cobbett, P., Q. Z. Yang, and G. I. Hatton (1987) Incidence of dye coupling among magnocellular paraventricular nucleus neurons in male rats is testosterone dependent. Brain Res. Bull. 18: 365-370.

Collins III, W. F. (1983) Organization of electrical coupling between frog lumbar motoneurons. J. Neurophysiol. 49: 730-744.

Dahl, G., and W. Berger (1978) Nexus formation in the myometrium during parturition and induced by estrogen. Cell Biol. Intern. Rep. 2: 381-387.

Demianczuk, N., M. E. Towell, and R. E. Garfield (1984) Myometrial electrophysiologic activity and gap junctions in the pregnant rabbit. Am. J. Obstet. Gynecol. 169: 485-491.

Erulkar, S. D., and R. W. Soller (1980) Interactions among lumbar motoneurons on opposite sides of the frog spinal cord: Morphological and electrophysiological studies. J. Comp. Neurol. 192: 473-488.

Flagg-Newton, J., I. Simpson, and W. Loewenstein (1979) Permeability of the cell-to-cell membrane channels in mammalian gap junctions. Science 205: 404-407.

Forger, N. G., and S. M. Breedlove (1987) Seasonal variation in mammalian striated muscle mass and motoneuron morphology. J. Neurobiol. 18: 155-165.

Fulton, B. P., R. Miledi, and T. Takahashi (1980) Electrical synapses between motoneurons in the spinal cord of the newborn rat. Proc. $R$. Soc. Lond. [Biol.] 208: 115-120.

Furshpan, E. J. (1964) Electrical transmission of an excitatory synapse in a vertebrate brain. Science $244: 878-880$.

Furshpan, E. J., and D. D. Potter (1959) Transmission at the giant motor synapses of the crayfish. J. Physiol. (Lond.) 145: 289-325.

Garfield, R. E., M. S. Kannan, and E. E. Daniel (1980) Gap junction formation in myometrium: Control by estrogens, progesterone, and prostaglandins. Am. J. Physiol. 238: C81-C89.

Gogan, P., J. P. Gueritaud, G. Horcholle-Bossavit, and S. Tyc-Dumont (1977) Direct excitatory interactions between spinal motoneurones of the cat. J. Physiol. (Lond.) 272: 755-767. 
Grinnell, A. D. (1966) A study of the interaction between motoneurones in the frog spinal cord. J. Physiol. (Lond.) 182: 612-648.

Grinnell, A. D. (1970) Electrical interaction between antidromically stimulated frog motoneurones and dorsal root afferents: Enhancement by gallamine and TEA. J. Physiol. (Lond.) 210: 17-43.

Hama, K. (1961) Some observations on the fine structure of the giant fibers of the crayfish (Cambarus virilus and Cambarus clarkil) with special reference to the submicroscopic organization of the synapses. Anat. Rec. 161: 275-293.

Hart, B. L. (1967) Testosterone regulation of sexual reflexes in spinal male rats. Science 155: 1283-1284.

Hart, B. L. (1973) Effects of testosterone propionate and dihydrotestosterone on penile morphology and sexual reflexes of spinal male rats. Horm. Behav. 4: 239-246.

Hart, B. L., and P. Y. Melese-d'Hospital (1983) Penile mechanisms and the role of the striated penile muscles in penile reflexes. Physiol. Behav. 31: 807-813.

Kerns, J. M., and A. Peters (1974) Ultrastructure of a large ventrolateral dendritic bundle in the rat ventral horn. J. Neurocytol. 3: 533555.

Korn, H., C. Sotelo, and F. Crepel (1973) Electrotonic coupling between neurons in rat lateral vestibular nucleus. Exp. Brain Res. 16: 255-275.

Kurz, E. M., D. R. Sengelaub, and A. P. Arnold (1986) Androgens regulate dendritic length of sexually dimorphic mammalian motoneurons in adulthood. Science 232: 395-398.

Larsen, W. J. (1983) Biological implication of gap junction structure, distribution and composition: A review. Tissue Cell 15: 645-671.

Leedy, M. G., M. S. Beattie, and J. C. Bresnahan (1987) Testosterone induced plasticity of synaptic inputs to adult mammalian motoneurons. Brain Res. 424: 386-390.

Llinás, R., R. Baker, and C. Sotelo (1974) Electrotonic coupling between neurons in cat inferior olive. J. Neurophysiol. 37: 560-571.

Loewenstein, W. R. (1981) Junctional intercellular communication: The cell-to-cell membrane channel. Physiol. Rev. 61: 829-913.

MacKenzie, L. W., and R. E. Garfield (1985) Hormonal control of gap junction in the myometrium. Am. J. Physiol. 248: C296-C308.

Matsumoto, A., P. E. Micevych, and A. P. Arnold (1987) Androgenic organization of synaptic inputs to spinal motoneurons in adult rats. Soc. Neurosci. Abstr. 13: 165.

Matsumoto, A., P. E. Micevych, and A. P. Arnold (1988) Androgen regulates synaptic input to motoneurons of the adult rat spinal cord. J. Neurosci. 8: 4168-4176.

McKenna, K. E., and I. Nadelhaft (1986) The organization of the pudendal nerve in the male and female rat. J. Comp. Neurol. 268: 532-549.

McNutt, N. S., and R. Weinstein (1970) The ultrastructure of the nexus: A correlated thin-section and freeze-cleave study. J. Cell Biol. 47: 666-688.

Merk, F. B., C. R. Botticelli, and J. T. Albright (1972) An intercellular response to estrogen by granulosa cells in the rat ovary: An electron microscope study. Endocrinology 90: 992-1007.
Merk, F. B., P. W. L. Kwan, and I. Leav (1980) Gap junctions in the myometrium of hypophysectomized estrogen-treated rats. Cell Biol. Intern. Rep. 4: 287-294.

Nelson, P. G. (1966) Interaction between spinal motorneurons of the cat. J. Neurophysiol. 29: 275-287.

Payton, B. W., M. V. L. Bennett, and G. D. Pappas (1969) Membranes at an electronic synapse. Science 166: 1641-1643.

Peracchia, C. (1980) Structure correlates of gap junction permeation. Intern. Rev. Cytol. 66: 81-146.

Pinching, A. J., and T. P. S. Powell (1971) The neuropil of the glomeruli of the olfactory bulb. J. Cell Sci. 9: 347-377.

Purohil, R. C., and S. D. Beckell (1976) Penile pressures and muscle activity associated with erection and ejaculation in the dog. Am. J. Physiol. 231: 1343-1348.

Revel, J. P., and M. J. Karnovsky (1967) Hexagonal array of subunits in intercellular junctions of the mouse heart and liver. J. Cell Biol. 33: $\mathrm{C} 7-\mathrm{C} 12$.

Robertson, J. D. (1963) The occurrence of a subunit pattern in the unit membranes of club endings in Mauthner cell synapses in gold fish brains. J. Cell Biol. 19: 201-221.

Rose, R. D., and W. F. Collins III (1985) Crossing dendrites may be a substrate for synchronized activation of penile motoneurons. Brain Res. 337: 373-377.

Sachs, B. D. (1982) Role of penile muscles in penile reflexes, copulation, and induction of pregnancy in rats. J. Reprod. Fertil. 66:433443.

Schnitzlein, H. N., and H. K. Brown (1975) Spinal motoneurons of the goldfish (Carassius auratus). Brain Behav. Evol, 12: 207-228.

Schroder, H. D. (1980) Organization of the motoneurons innervating the pelvic muscles of the rat. J. Comp. Neurol. 192: 567-587.

Sotelo, C., and H. Korn (1978) Morphological correlates of electrical and other interactions through low resistance pathways between neurons of the vertebrate central nervous system. Intern. Rev. Cytol. 55 : 67-107.

Sotelo, C., and J. Taxi (1970) Ultrastructural aspects of electrotonic junction in the spinal cord of the frog. Brain Res. 17: 137-141.

Spray, D. C., and M. V. L. Bennett (1985) Physiology and pharmacology of gap junctions. Annu. Rev. Physiol. 47: 281-303.

Tobias, M. L., and D. B. Kelley (1988) Electrophysiology and dyecoupling are sexually dimorphic characteristics of individual laryngeal muscle fibers in Xenopus laevis. J. Neurosci. 8: 2422-2429.

Unwin, P. N. T., and G. Zampighi (1980) Structure of the junction between communicating cells. Nature 283: 545-549.

Washizu, Y. (1960) Single spinal motoneurons excitable from two different antidromic pathways. Jpn. J. Physiol. 10: 121-131.

Waxman, S. G. (1979) Electron microscopy of synapses in the reptile spinal cord. Neurosci. Lett. 13: 237-242.

Zampighi, G., J. M. Corless, and J. D. Robertson (1980) On gap junction structure. J. Cell Biol. 86: 190-198. 